\title{
Immune Response in Tuberculosis - CD4/CD68 Epitope Mapping
}

\author{
Kavitha $\mathrm{A}^{1}$, Priavadhana Rajan Prasaad ${ }^{2 *}$, Bheema Rao $\mathrm{G}^{1}$ and Hemalatha Ganapathy ${ }^{1}$ \\ ${ }^{1}$ Sree Balaji Medical College and hospital, Chromepet, Chennai, India \\ ${ }^{2}$ Department of Pathology, ESIC Medical College and PGIMSR, KK Nagar, Chennai, India
}

\begin{abstract}
Background: Tuberculosis, one of the oldest recorded human afflictions, is one of the biggest killers among the infectious diseases despite the use of vaccination and antibiotics.From 21 st century, tuberculosis (TB) had caused illness and death of more than eight million individuals. Every year in India 600,000 deaths occur due to TB. The incidence and prevalence are 1.5 and 3.5 million respectively.This is further complicated by the emergence of multi-resistant strains of Mycobacterium tuberculosis and the HIV co-pandemic.

Aim of this study was to elaborate immunological framework of tuberculous lesions through its evolution which helps to understand regional host response and counter-measures to Mycobacterium tuberculosis.

Materials and Methods: This was a retrospective study on fifteen cases which were diagnosed as tuberculous lymphadenitis (four early lesions, six evolving lesions and five late lesions) received over one year in a tertiary medical college hospital in south India. Histopathological features of tuberculous granuloma and its immunological evolution were studied.

Results: Early lesions were negative for CD4, with focal positivity for CD68 and diffuse strong positivity for CD45. Evolving lesions showed focal positivity with CD4, strong positivity for CD68 and diffuse peripheral positivity with CD45. In well-formed granulomas of the late lesions, networking of CD4 cells was seen along with CD68 positivity inside the granuloma and very few CD45 positive cells.

Conclusion: The accumulation of MTb-specific T cells at the site of infection may prove as useful diagnostic marker for an accurate and rapid diagnosis of active TB.Correlation of immunology and pathology will contribute significantly to the design of novel intervention strategies. Thus, this study emphasizes on complex, dynamic and delicate interactions between mycobacteria and cells of their hosts.
\end{abstract}

Keywords: Tuberculous Lymphadenitis, Immunity, Granuloma, Immunohistochemistry, CD4 Cells, Caseous Necrosis, Histopathology

\section{Introduction}

Tuberculosis, one of the oldest recorded human afflictions, is one of the biggest killers among the infectious diseases despite the use of vaccination and antibiotics ${ }^{[1]}$. From $21^{\text {st }}$ century, tuberculosis (TB) had caused illness and death of more than eight million individuals. Every year in India 600,000 deaths occur due to TB. The incidence and prevalence are 1.5 and 3.5 million respectively. ${ }^{[2]}$ This is further complicated by the emergence of multi-resistant strains of Mycobacterium tuberculosis and the HIV co-pandemic. ${ }^{[3]}$

Tuberculosis (TB) has plagued mankind for eras. The importance of diagnostic research on tuberculosis cannot be exaggerated because one-third of the world population carries a latent infection with Mycobacterium tuberculosis (MTb). Identifying and treating those who progress to disease and transmit infection to contacts are critical for successful control. Immunity to TB depends critically on the generation of effective CD4+ T-cell responses. Early T-cell responses are effective in controlling steady-state infection. There is a serious period, before the activation of the T-cell response, in which MTb is able to establish infection. An understanding of the factors that regulate early T-cell activation therefore leads to better control of the disease. Real progress will require more detailed knowledge of the host immune responses. Specific areas of that require elaborate research include studying the roles of various immune cell subsets, the antigens recognized by immune effector cells, the effector mechanisms involved, the mechanisms of pathogen avoidance, and the regulation of the innate and adaptive immune responses. CD4+ and CD8 $+\mathrm{T}$ cells exhibit different spatial and temporal distributions during infection that may contribute to or command cellular functions.

Aim of this study was to elaborate immunological framework of tuberculous lesions through its evolution which helps to understand regional host response and counter-measures to Mycobacterium tuberculosis.

\section{Materials and Methods:}

This was a retrospective study, conducted in a tertiary care medical college hospital in south India over a period of 
one year. Fifteen cases of lymph node biopsies reported as tuberculous lymphadenitis were included in the study. Clinical details like symptoms of presentation, groups of nodes involved and association with HIV status obtained. The lymph nodes are routinely processed and stained with Hematoxylin and Eosin stain and Acid fast stain. Various histomorphological features like neutrophilic infiltration, presence of caseous necrosis, presence of well-formed or ill formed granulomas, presence of Langhans cells and adjacent lymph node architecture were documented in histopathological findings. Further, in all these lymph node biopsies, immunohistochemical stains for CD4, CD 45 and CD 68 were performed and findings documented. Immunohistochemistry was done using Heat Induced Epitope Retrieval method (HIER) and stained with Diamino-benzidine (DAB) chromogen which gives a brown reaction product.

\section{Results}

Fifteen cases oflymph node biopsies reported as tuberculosis were included in this study. These lesions of tuberculous lymphadenitis were further classified as early stage, evolving stage and late stage tuberculous lymphadenitis. Lymph nodes with neutrophils and fragmented neutrophils in the absence of Langhans giant cells are included under early lesion (group 1) which included 4 cases (FIG 1-4); Lymph nodes showing necrosis, Langhans giant cells were included in evolving lesion (group 2) which had 6 cases (FIG 5-8) and lymph nodes with well-formed granulomas with necrosis, epithelioid cells, Langhans giant cells surrounded by lymphocytes were included in late lesions (group 3) which had 5 cases (FIG 9-12). After categorization into the above mentioned groups, the expression of the immunohistochemical markers CD 4, CD 68 and CD 45 were observed and evaluated as in (Table 1).

Table 1: Immunohistochemical expression patterns in various lesions of tuberculous lymphadenitis.

\begin{tabular}{|l|l|l|l|l|}
\hline TYPE OF LESION & H AND E & CD 68 & CD 4 & CD 45 \\
\hline EARLY LESION & $\begin{array}{l}\text { Shows neutrophils } \\
\text { and necrosis }\end{array}$ & $\begin{array}{l}\text { Focally positive } \\
\text { FIG 2 }\end{array}$ & $\begin{array}{l}\text { Negative } \\
\text { FIG 3 }\end{array}$ & $\begin{array}{l}\text { Diffuse strong positive } \\
\text { FIG 4 }\end{array}$ \\
\hline EVOLVING LESION & $\begin{array}{l}\text { Shows necrosis and } \\
\text { giant cells }\end{array}$ & $\begin{array}{l}\text { Strongly positive } \\
\text { FIG 6 }\end{array}$ & $\begin{array}{l}\text { Focally positive } \\
\text { FIG 7 }\end{array}$ & $\begin{array}{l}\text { Diffuse positive } \\
\text { peripherally FIG 8 }\end{array}$ \\
\hline LATE LESION & $\begin{array}{l}\text { Well-formed } \\
\text { granulomas }\end{array}$ & $\begin{array}{l}\text { Positive inside } \\
\text { granuloma FIG 10 }\end{array}$ & $\begin{array}{l}\text { Networking of granulomas } \\
\text { with strong positivity FIG 11 }\end{array}$ & $\begin{array}{l}\text { Very few cells stained } \\
\text { positive FIG 12 }\end{array}$ \\
\hline
\end{tabular}
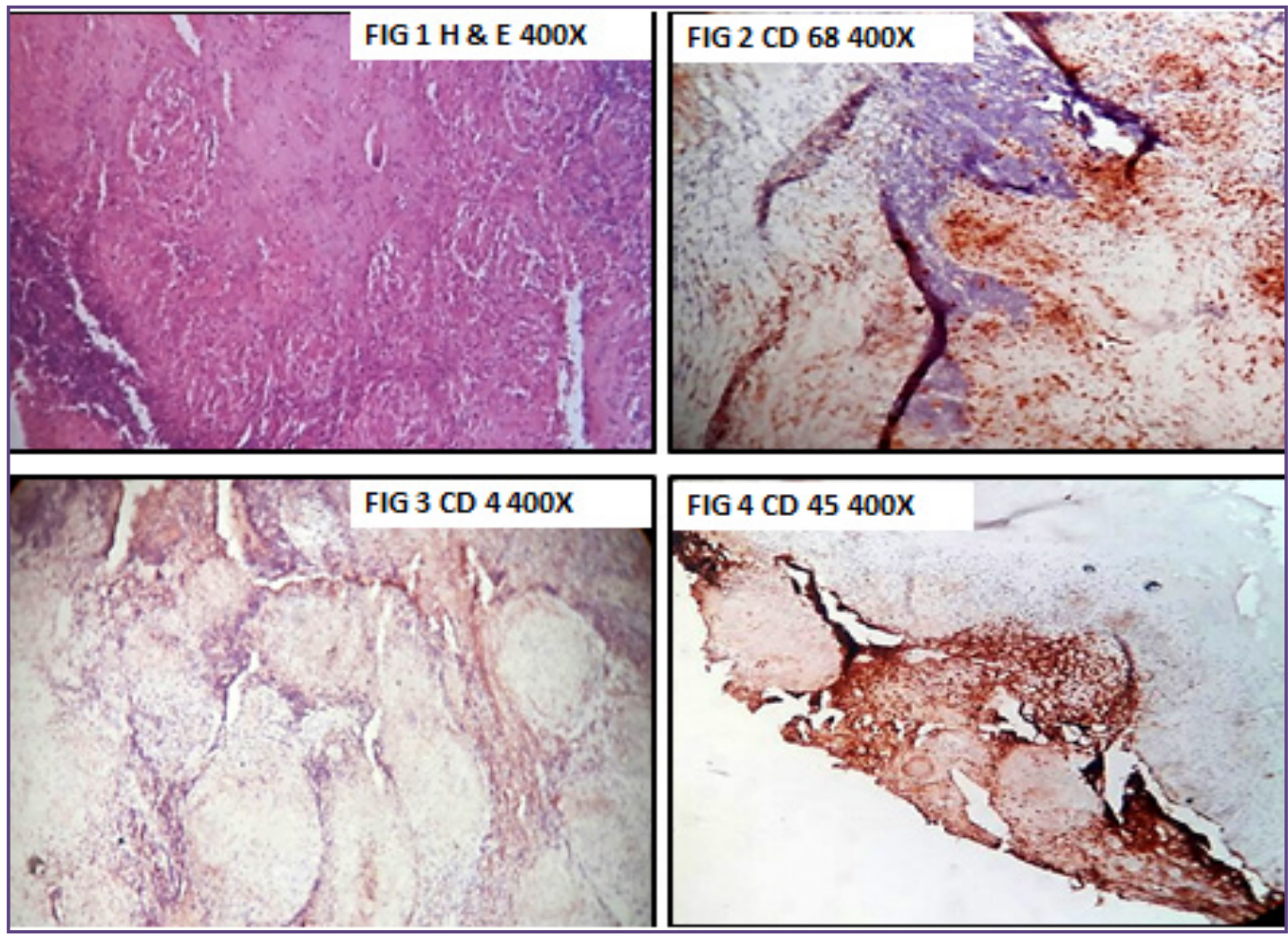

FIG 1 ; High power view of early tuberculous lesion, (H\&E), FIG 2 : Immunohistochemistry ofCD 68 positivity in early lesions, FIG 3 : Immunohistochemistry of CD 4 staining absent in early lesions, FIG 4: Immunohistochemistry of CD 45 strong positivity in early lesions. 

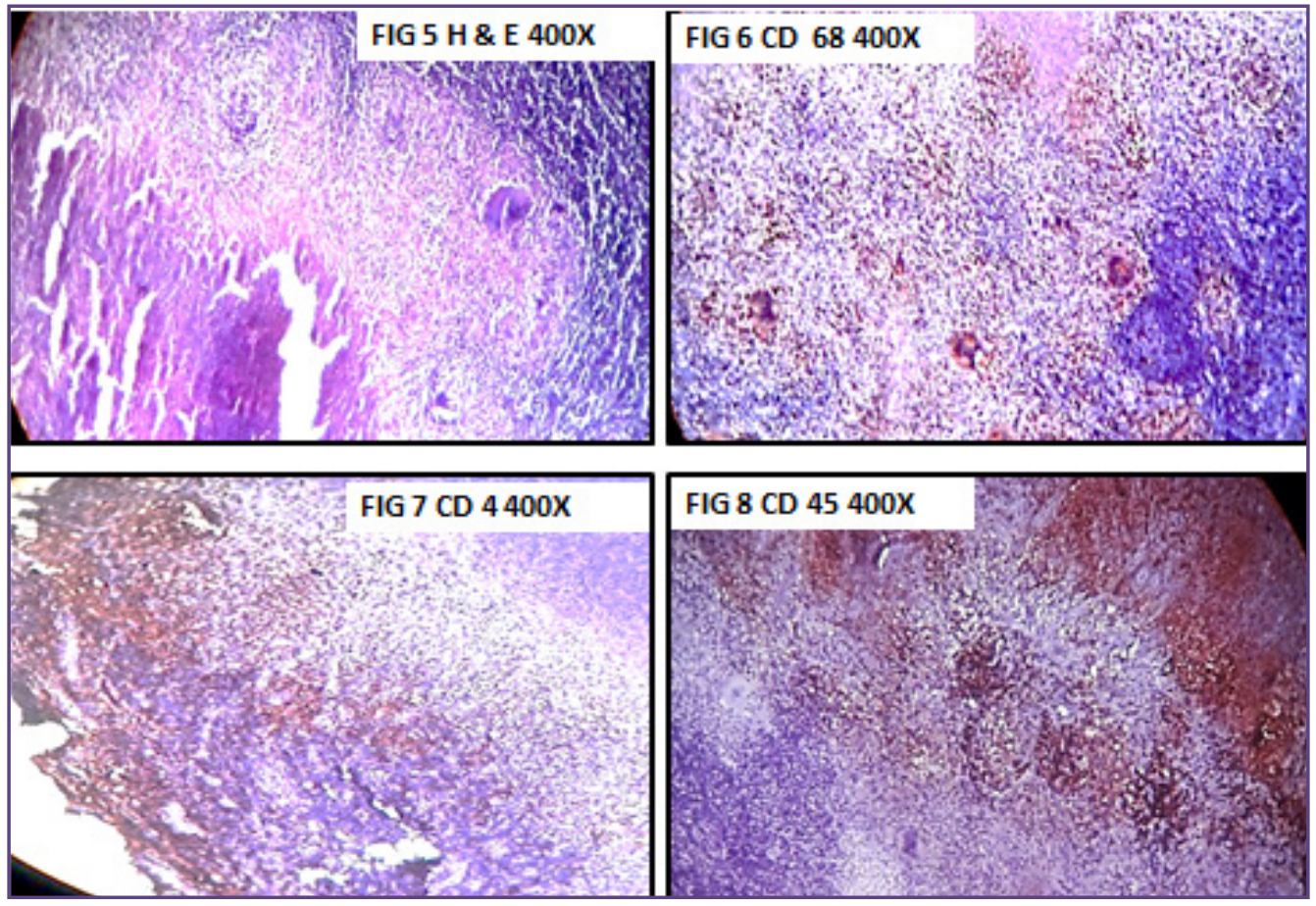

FIG 5: High power view of evolving lesion with granulomas and Langhan giant cells, (arrow - Langhan's giant cells) Hematoxylin and eosin stain, FIG 6 :Immunohistochemistry of CD 68 strong positivity in evolving lesions (arrow - Langhan's giant cells), FIG 7 : Immunohistochemistry of CD 4 focal staining in evolving lesions, FIG 8 : Immunohistochemistry of CD 45 staining in evolving lesions.
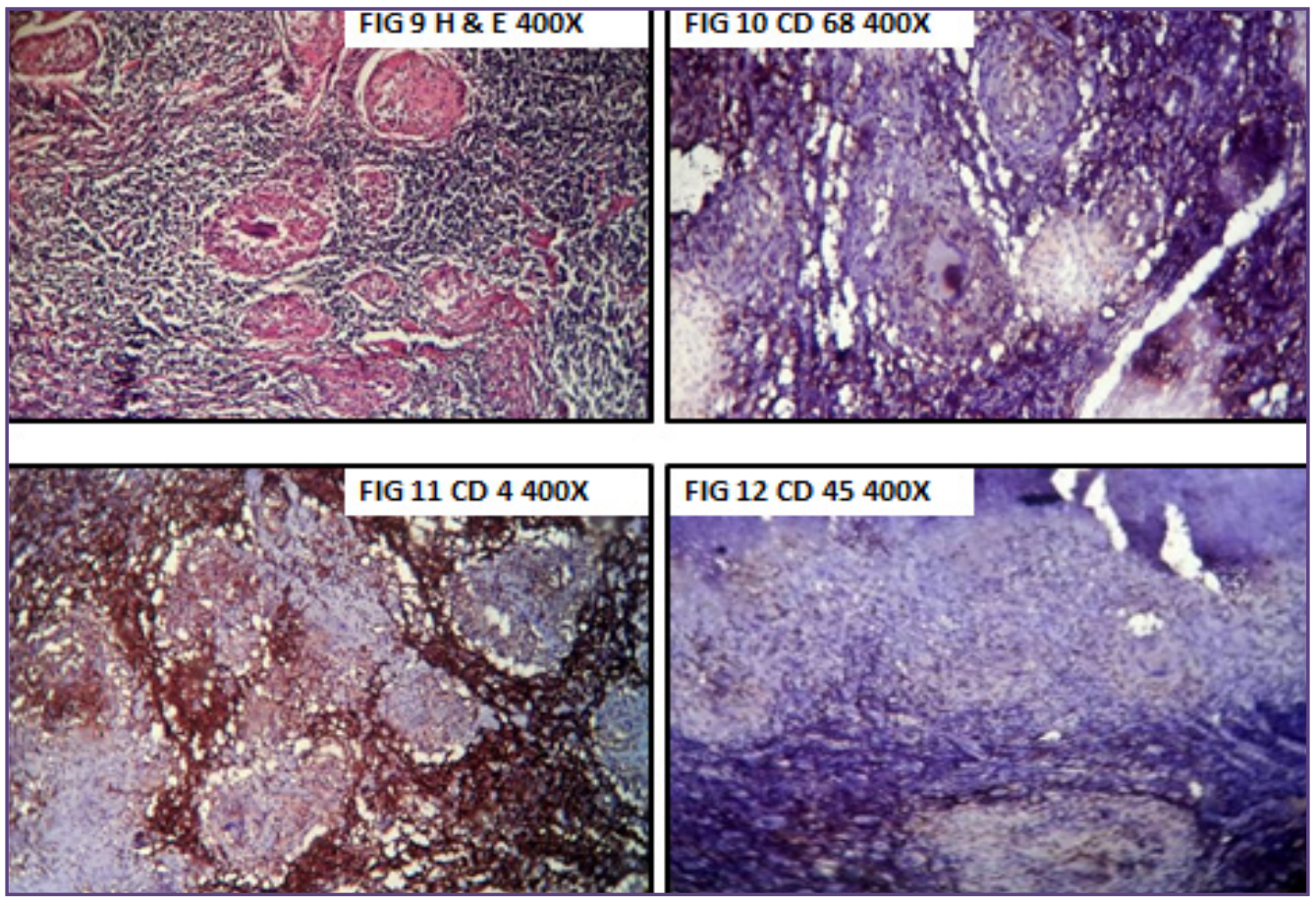

FIG. 9 :High power view of well-formed granulomas (arrow - well-formed granuloma with Langhan's giant cell), H\&E stain, FIG 10: Immunohistochemistry ofCD 68 absent staining in well-formed granulomas, FIG 11:Immunohistochemistry ofCD 4 strong positivity with networking around granulomas, FIG 12 : Immunohistochemistry ofCD 45 staining in well-formed granulomas. 


\section{Discussion}

Immunological biomarkers distinguish spectrum of Mycobacterium tuberculosis infection. Immunological events are at the hub of TB pathogenesis, since they are liable for both tissue damage and protection. ${ }^{[4]}$

Bissel $\mathrm{M}$ et al showed various stages and outcomes of $\mathrm{MTb}$ infection connected with particular immunological events. ${ }^{[5]}$ The present study explores connection between the histopathological events and development of MTb infection and the evolution of immune responses to tubercle bacillus.

Russell D et al. showed tubercle bacilli interrelate with immune cells and various host cells and interact with each other to form the granulomas, a dynamic multicellular structure, that is the histopathological hallmark of MTb infection. The granuloma acts as a site of immune cell priming. In granulomas, macrophages predominate in the inner cellular layers as multinucleated giant cells, epithelioid cells, or foamy cells. ${ }^{[6]}$

Ulrichs et al showed $\mathrm{T}$ lymphocytes expressing T-cell receptors are also present. CD4+T cells are localized in both inner and outer cellular layers, while $\mathrm{CD} 8+\mathrm{T}$ cells are found mostly in the outer cellular layer. The outer cellular layer also contains B cell-rich aggregates, which include bacillus-laden antigen presenting cells and $\mathrm{T}$ lymphocytes. Typical granuloma includes a central necrotic core. Some bacilli are found in the necrotic core, but most are located at the interface between the necrotic core and the macrophage-rich, inner cellular layer. ${ }^{17,8]}$

Uhrlichs et al showed, as disease progresses, granulomas tend to be less organized ${ }^{[7,8]}$. Kaplan $G$ et al. showed loss of organization in the granuloma alters the interactions between immune cells and correlates with tissue destruction, as indicated in active TB. ${ }^{{ }^{[9}}$ Barry $\mathrm{S}$ et al showed granuloma progression is associated with increased bacterial numbers, this may be favored by the local selective reduction of $\mathrm{T}$ cells, which diminishes T-cell-macrophage interactions. ${ }^{[10,11]}$ Disorganization of advanced granulomas may also facilitate bacterial dissemination to other areas and other organs, with formation of new granulomas.

Lin P. L., et al stated that there are many variants of the tuberculous granuloma which differ in cellular composition and structure. ${ }^{[12]}$ Some granulomas are rich in granulocytes. Fenhalls $\mathrm{G}$ et al. showed other variants of granulomas vary with regard to T-cell composition with few granulomas staining positive for $\mathrm{CD} 4+\mathrm{T}$ cells and about a half staining positive for $\mathrm{CD} 8+\mathrm{T}$ cells. ${ }^{[13]}$
Barry $\mathrm{C}$ et al stated that while the architecture of the granuloma typically changes with the evolution of infection, different types of granulomatous lesions are also found in the same individual, either with active disease or with latent infection. ${ }^{[14]}$

The immunological priming, occurs at the interface between the macrophage-rich inner layer and the surrounding T-cell-rich outer layer. Since $\mathrm{T}$ cells in this layer are predominantly $\mathrm{CD} 4+$ cells, they are more likely to interact with APCs than CD8+T cells, which are found mostly in the outer cellular layer. Additional priming sites for B cells and $\mathrm{T}$ cells include the follicle-like structures found in the outer cellular layer, which are rich in B cells, CD4+and CD8 $+\mathrm{T}$ cells, and infected APCs. In these follicles, B cells are found at different states of differentiation.

This complex interaction between tubercle bacilli and immune cells lead to the view that the spectrum of the clinical manifestations is accompanied by a corresponding spectrum of tissue damage and immune responses. If so, particular stages of the MTb infection are associated with specific phenotypes, cytokine levels, and/or antibody profiles. Simultaneous detection of antigen-specific T-cell responses are still being developed ${ }^{[15,16]}$. Advanced methods should make it possible to characterize the immunological spectrum of MTb infection by assessing large numbers of mediators of the cellular and humoral response to many antigens of the tubercle bacillus.

\section{Conclusion}

The accumulation of MTb-specific T cells at the site of infection may prove as useful diagnostic marker for an accurate and rapid diagnosis of active TB. Correlation of immunology and pathology will contribute significantly to the design of novel intervention strategies. Thus, this study emphasizes on complex, dynamic and delicate interactions between mycobacteria and cells of their hosts.

\section{Ethical Approval}

Obtained from institutional ethical and research committee

\section{References:}

1. Laniado-Laborin R. Recent Advances in the Diagnosis and Treatment of Drug-Resistant Tuberculosis. Current Respiratory Medicine Reviews. 2017;13.

2. Ling D, Flores L, Riley L, Pai M. Commercial NucleicAcid Amplification Tests for Diagnosis of Pulmonary Tuberculosis in Respiratory Specimens: Meta-Analysis and Meta-Regression. PLoS ONE. 2008;3(2):e1536.

3. Winslow G, Cooper A, Reiley W, Chatterjee M, Woodland D. Early T-cell responses in tuberculosis immunity. Immunological Reviews. 2008;225(1):284-299. 
4. Dorhoi A, Reece S, Kaufmann S. For better or for worse: the immune response against Mycobacterium tuberculosis balances pathology and protection. Immunological Reviews. 2011;240(1):235-251.

5. Bissell M. Interferon- $\gamma$ release assays for the diagnosis of latent Mycobacterium tuberculosis infection: a systematic review and meta-analysis. Yearbook of Pathology and Laboratory Medicine. 2012;2012:298-299.

6. Russell D. Who puts the tubercle in tuberculosis?. Nature Reviews Microbiology. 2006;5(1):39-47.

7. Ulrichs T, Kaufmann S. New insights into the function of granulomas in human tuberculosis. The Journal of Pathology. 2005;208(2):261-269.

8. Ulrichs T, Kosmiadi G, Jörg S, Pradl L, Titukhina M, Mishenko V et al. Differential Organization of the Local Immune Response in Patients with Active Cavitary Tuberculosis or with Nonprogressive Tuberculoma. The Journal of Infectious Diseases. 2005;192(1):89-97.

9. Kaplan G, Post F, Moreira A, Wainwright H, Kreiswirth B, Tanverdi $\mathrm{M}$ et al. Mycobacterium tuberculosis Growth at the Cavity Surface: a Microenvironment with Failed Immunity. Infection and Immunity. 2003;71(12):7099-7108.

10. Azikin W. Matrix Metalloproteinase-9 (MMP-9) Level in Tuberculosis Exposed and Infected Children. American Journal of Health Research. 2017;5(1):7.
11. Barry S, Breen R, Lipman M, Johnson M, Janossy G. Impaired antigen-specific CD4+ T lymphocyte responses in cavitary tuberculosis. Tuberculosis. 2009;89(1):48-53.

12. Lin P, Rodgers M, Smith L, Bigbee M, Myers A, Bigbee $\mathrm{C}$ et al. Quantitative Comparison of Active and Latent Tuberculosis in the Cynomolgus Macaque Model. Infection and Immunity. 2009;77(10):4631-4642.

13. Fenhalls G, Stevens L, Bezuidenhout J, Amphlett G, Duncan K, Bardin P et al. Distribution of IFN-, IL-4 and TNF- protein and CD8 T cells producing IL-12p40 mRNA in human lung tuberculous granulomas. Immunology. 2002;105(3):325-335.

14. Barry C, Boshoff H, Dartois V, Dick T, Ehrt S, Flynn J et al. The spectrum of latent tuberculosis: Rethinking the biology and intervention strategies. Nature Reviews Microbiology. 2009.

15. Hadrup S, Bakker A, Shu C, Andersen R, van Veluw J, Hombrink $\mathrm{P}$ et al. Parallel detection of antigen-specific T-cell responses by multidimensional encoding of MHC multimers. Nature Methods. 2009;6(7):520-526.

16. Nemeth J, Winkler H, Zwick R, Rumetshofer R, Schenk $\mathrm{P}$, Burghuber $\mathrm{O}$ et al. Recruitment of Mycobacterium tuberculosis specific CD4+T cells to the site of infection for diagnosis of active tuberculosis. Journal of Internal Medicine. 2009;265(1):163-168.

*Corresponding author:

Dr. Priavadhana Rajan Prasaad, Assistant professor, Department of Pathology, ESIC Medical College and PGIMSR, KK Nagar, Chennai -78 Tamil Nadu, India Phone: +919677685015

Email: drpriarajan@gmail.com

Financial or other Competing Interests: None. 